\title{
Photocatalytic and Photoelectrochemical Degradation of Organic Compounds with All-Inorganic Metal Halide Perovskite Quantum Dots
}

\author{
Drialys Cardenas-Morcoso, ${ }^{\dagger}$ Andrés F. Gualdrón-Reyes, ${ }^{\dagger,}, \S$ Ana Beatriz Ferreira Vitoreti, ${ }^{\dagger, \perp, \#}$
}

Miguel García-Tecedor, ${ }^{\dagger}$ Seog Joon Yoon, ${ }^{\dagger}$ Mauricio Solis de la Fuente, ${ }^{\nabla}$ Iván Mora-Seró, ${ }^{*}{ }^{\dagger}$ (i) and Sixto Gimenez ${ }^{* \dagger} \dagger$

\author{
${ }^{\dagger}$ Institute of Advanced Materials (INAM), Universitat Jaume I, 12006 Castelló, Spain \\ ${ }^{\ddagger}$ Centro de Investigaciones en Catálisis (CICAT), Universidad Industrial de Santander, Sede UIS Guatiguará, Piedecuesta, \\ Santander, Colombia C.P. 681011 \\ ${ }^{\S}$ Centro de Investigación Científica y Tecnológica en Materiales y Nanociencias (CMN), Universidad Industrial de Santander, \\ Piedecuesta, Santander, Colombia C.P. 681011 \\ ${ }^{\perp}$ Department of Natural Science, Federal University of São João del-Rei, 36301-160 São João del-Rei, Brazil \\ ${ }^{\#}$ CAPES Foundation, Ministry of Education of Brazil, Brasília 70040-020, Brazil \\ ${ }^{\nabla}$ Lawrence Berkeley National Laboratory, Energy Technologies Area, 1 Cyclotron Road, Berkeley, California 94720, United States
}

Supporting Information

\begin{abstract}
Inspired by the outstanding optoelectronic properties reported for all-inorganic halide perovskite quantum dots (QDs), we have evaluated the potential of these materials toward the photocatalytic and photoelectrochemical degradation of organic compounds, taking the oxidation of 2-mercaptobenzothiazole (MBT) as a proof-of-concept. First, we determined electrochemically the energy levels of dispersions of perovskite QDs with different band gaps induced by the different ratios between halides ( $\mathrm{Br}$ and $\mathrm{I}$ ) and metallic cations $(\mathrm{Pb}$ and $\mathrm{Sn}$ ). Then, we selected $\mathrm{CsPbBr}_{3}$ QDs to demonstrate the photocatalytic and photoelectrochemical oxidation of MBT, confirming that hole injection takes place from $\mathrm{CsPbBr}_{3}$ QDs to $\mathrm{MBT}$, resulting in the total degradation of $\mathrm{MBT}$ as evidenced by electrospray mass spectrometry analyses. Although the stability and toxicity of these QDs are major issues to address in the near future, the results obtained in the present study open promising perspectives for the implementation of solar-driven catalytic strategies based on these fascinating materials.
\end{abstract}

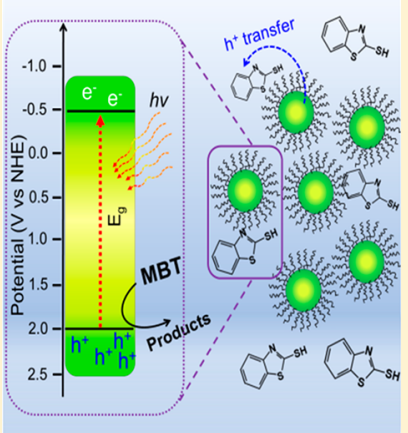

A ll-inorganic halide perovskite quantum dots (QDs) have emerged in the last 3 years with outstanding optoelectronic properties and promising stability. ${ }^{1,2}$ The high photoluminescence quantum yield (PLQY) of core nanoparticles with narrow PL spectra and reduced PL blinking, ${ }^{3}$ together with a low lasing threshold, ${ }^{4}$ enables these materials as excellent candidates for applications in photovoltaics and stimulated and light emission. ${ }^{5}$ The outstanding PLQY of perovskite QDs is clear evidence of the significant reduction of nonradiative recombination pathways. Consequently, after photoexcitation, these systems present a pool of photoexcited carriers whose extra energy can be used in an efficient radiative emission or taken advantage of in different ways, such as providing work in solar cells or driving diverse chemical reactions. These remarkable optoelectronic properties have been demonstrated in a few seminal studies of these materials for photocatalysis, with interesting examples for the degradation of organic dyes, ${ }^{6}$ functionalization of $\mathrm{C}-\mathrm{H}$ bonds in alkanes, ${ }^{7}$ and $\mathrm{CO}_{2}$ conversion into added value products. ${ }^{8-10}$ In this context, it is essential to provide a systematic approach to understand the suitability of perovskite QDs toward photoelectrochemical and photocatalytic applications. As a first step, careful assessment of the environmental and experimental conditions for photoelectrochemical tests is needed to control any chemical and photochemical interaction that can take place with perovskite QDs during operation. Next, the energy levels in the selected electrolyte must be determined, i.e., the conduction band (CB) minimum and valence band $(\mathrm{VB})$ maximum, to assess the potential of these materials to inject photogenerated carriers into an electrolytic or molecular acceptor under illumination, which is essential for photoelectrochemical and photocatalytic applications. Since the pioneering work from Bard and co-workers, ${ }^{11}$ who reported the correlation between the optical and electrochemical band gap in dispersions of CdS QDs, cyclic voltammetry (CV) measurements have been successfully employed to determine the band structure and quantum

Received: December 26, 2018

Accepted: January 23, 2019

Published: January 23, 2019 
(a)

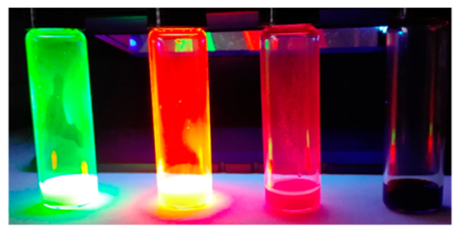

i

ii

iii

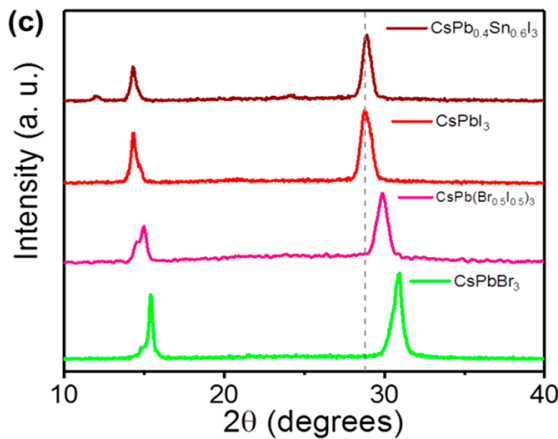

(b)

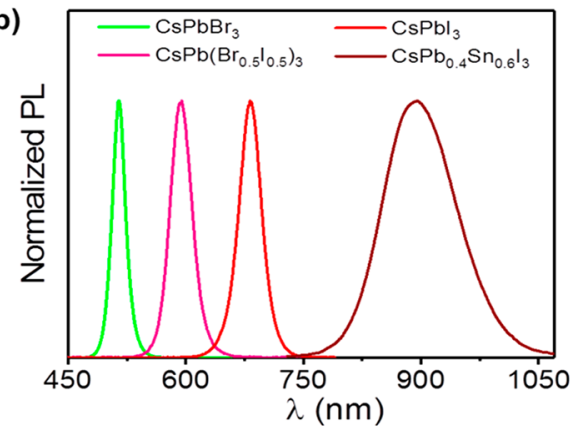

(d)

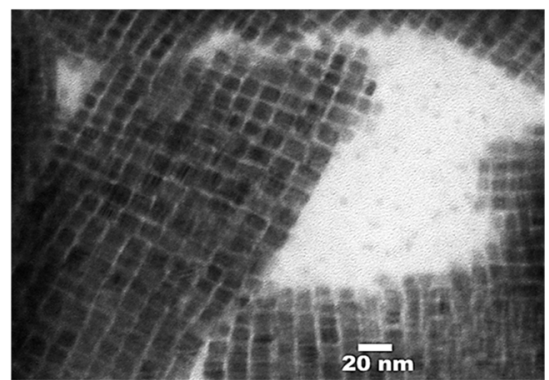

Figure 1. Optical and structural characterization of the different perovskite QDs studied. (a) Digital photograph of perovskite QDs solutions under UV light: i CsPbBr 3 , ii CsPbI $\mathrm{Pb}_{3}$, iii $\mathrm{CsPb}\left(\mathrm{I}_{0.5} \mathrm{Br}_{0.5}\right)_{3}$, and iv $\mathrm{CsPb}_{0.4} \mathrm{Sn}_{0.6} \mathrm{I}_{3}$. (b) Normalized PL spectra. (c) XRD diffractograms; the dashed vertical line is centered at the $\mathrm{CsPb}_{3}$ peak to provide direct visualization of the peak shifts due to the partial cation substitution and partial/total anion substitution. (d) Representative TEM picture of the $\mathrm{CsPbBr}_{3}$ QDs.

confinement effects in $\mathrm{CdSe}^{12,13}$ and $\mathrm{CdTe}^{14,15}$ QDs. More recently, $\mathrm{Nag}$ and co-workers studied the effect of halide composition in $\mathrm{CsPbX}_{3}(\mathrm{X}=\mathrm{Cl}, \mathrm{Br}, \mathrm{I})$ nanoparticles on the $\mathrm{VB}$ and $\mathrm{CB}$ positions and the effect on optical transition probabilities across these edges. ${ }^{16}$ On the other hand, CV has been also employed as a relevant interrogating tool on hybrid organic-inorganic perovskite films, ${ }^{17}$ where the main difference with nanoparticle dispersions is that the electrochemical reactions are kinetically controlled, instead of diffusion controlled. ${ }^{12}$

Herein, we have selected four different perovskite QDs solutions with different band gaps, covering the whole visible spectrum by the variation of the nominal compositions: $\mathrm{CsPbBr}, \mathrm{CsPb}_{3}, \mathrm{CsPb}_{0.4} \mathrm{Sn}_{0.6} \mathrm{I}_{3}$, and $\mathrm{CsPb}\left(\mathrm{Br}_{0.5} \mathrm{I}_{0.5}\right)_{3}$. Figure 1 shows the typical structural and photophysical properties of the $\mathrm{CsPbX}_{3}(\mathrm{X}=\mathrm{Br}, \mathrm{I})$ and mixed $\mathrm{CsPbBr}_{1.5} \mathrm{I}_{1.5}$ and $\mathrm{CsPb}_{0.4} \mathrm{Sn}_{0.6} \mathrm{I}_{3}$ QDs perovskites, prepared by hot-injection method (see the Supporting Information for further details of experimental methods). Under UV light, highly luminescent nanocrystals were obtained (Figure 1a), featuring a wide variety of colors as a consequence of the increase of the iodine/bromine ratio, ${ }^{1}$ or the cation was interchanged in the $\mathrm{B}$-position of the $\mathrm{ABX}_{3}$-type structure, ${ }^{18}$ inducing band gap narrowing. The same trend is also reflected in the photoluminescence (PL) and absorbance spectra (Figure $1 \mathrm{~b}$ and Supporting Information Figure S2) obtained for each tested material, where a red shift of both the emission peak and the absorption band edge is observed. In the case of the $\mathrm{CsPb}_{0.4} \mathrm{Sn}_{0.6} \mathrm{I}_{3}$ QDs, the partial substitution of $\mathrm{Pb}$ by $\mathrm{Sn}$ strengthens the $\mathrm{B}-\mathrm{X}$ bond in the perovskite, increasing/lowering the $\mathrm{VB} / \mathrm{CB}$ energy position. ${ }^{18} \mathrm{On}$ the other hand, as with $\mathrm{CsPbX}_{3}(\mathrm{X}=\mathrm{Br}, \mathrm{I})$ QDs, the mixed $\mathrm{CsPb}\left(\mathrm{Br}_{0.5} \mathrm{I}_{0.5}\right)_{3}$ and $\mathrm{CsPb}_{0.4} \mathrm{Sn}_{0.6} \mathrm{I}_{3}$ QDs exhibited a symmetric emission feature at 683 and $893 \mathrm{~nm}$, respectively, characteristic of homogeneous solid solutions. ${ }^{1}$
The crystalline structure of the QDs was characterized by $\mathrm{XRD}$, as shown in Figure 1c. Two representative peaks are associated with the (100) and (200) planes from the perovskite structure with a cubic phase (JCPDS card \# 00054-0752). ${ }^{19}$ Furthermore, the increase of $\mathrm{Br}$ content is reflected in a shift of the peak positions to higher Bragg angles. This is due to the decrease of the ionic radius of the halide in the material, reducing the $\mathrm{Pb}-\mathrm{X}$ bond length in the lattice. ${ }^{20,21}$ The incorporation of $\mathrm{Sn}$ into $\mathrm{CsPb}_{3}$ to obtain the mixed cation $\mathrm{CsPb}_{0.4} \mathrm{Sn}_{0.6} \mathrm{I}_{3}$ QDs led to a slight shift of the perovskite peak position compared to $\mathrm{CsPbI}_{3}$. However, a small peak at around $12^{\circ}$ appeared, ascribed to trace amounts of impurities such as $\mathrm{SnI}_{2} / \mathrm{SnI}_{4}$ or their mixtures. ${ }^{22}$ A representative TEM image of the $\mathrm{CsPbBr}_{3}$ QDs is shown in Figure 1d, revealing a particle size between 10 and $15 \mathrm{~nm}$ with the characteristic cubic morphology of the perovskite crystalline structure, which is identical for all of the systems tested (see Supporting Information Figure S3, where the size distribution is also indicated).

As a fundamental preliminary step in our study, we conducted a detailed survey of different electrolyte/solvent combinations in order to ascertain the stability of the perovskite QDs solutions during the different photocatalytic/ photoelectrochemical tests (see Supporting Information Table $\mathrm{S} 1$ ). We found that the tetrabutylammonium hexafluorophosphate dissolved in dichloromethane $\left(\mathrm{Bu}_{4} \mathrm{NPF}_{6} / \mathrm{DCM}\right)$ was the most stable environment, in good agreement with a recent report on hybrid halide perovskites. ${ }^{23}$

In the electrochemical measurements with QDs dispersions, charge transfer between the $\mathrm{Pt}$ working electrode and the perovskite QDs is reflected as anodic $\left(\mathrm{A}_{1}\right)$ and cathodic peaks $\left(C_{1}\right)$ in the cyclic voltammograms, corresponding to the band edge positions, i.e., $\mathrm{VB}$ and $\mathrm{CB}$, respectively. The potential difference between $A_{1}$ and $C_{1}$ peaks is referred to as the quasiparticle band gap $\left(E_{\mathrm{g}}{ }^{\mathrm{qp}}\right)^{12}$ and should be close to the optical 
(a)

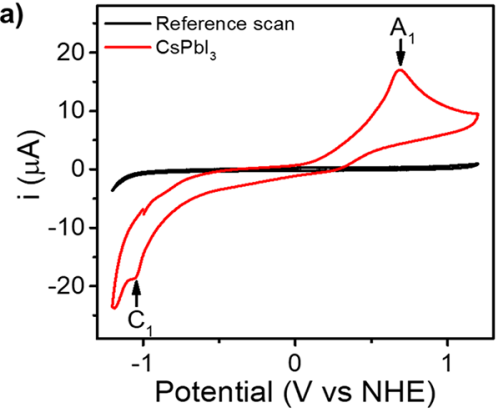

(c)

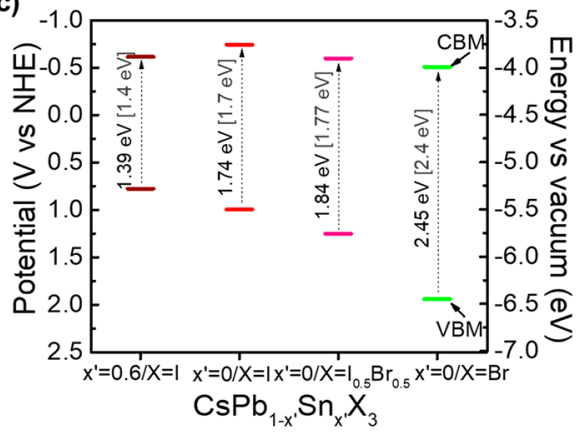

(b)
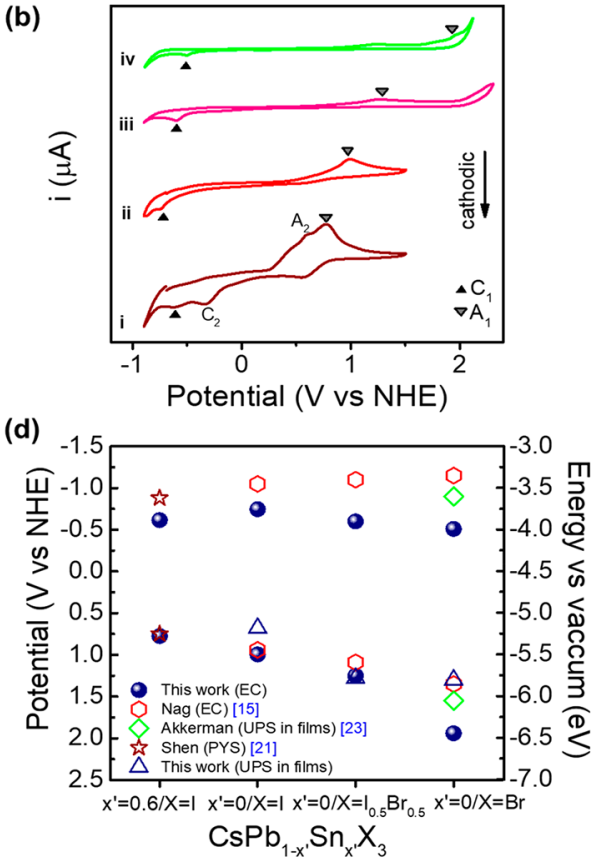

Figure 2. $\mathrm{CV}$ of the perovskite QDs investigated, recorded at $100 \mathrm{mV} \mathrm{s}^{-1}$ : (a) $\mathrm{CsPbI}_{3}$ (reference scan on a $100 \mathrm{mM} \mathrm{Bu}_{4} \mathrm{NPF}_{6}$ in $\mathrm{DCM}$ solution is also shown), (b) i $\mathrm{CsPb}_{0.4} \mathrm{Sn}_{0.6} \mathrm{I}_{3}$, ii CsPbI${ }_{3}$, iii $\mathrm{CsPb}\left(\mathrm{I}_{0.5} \mathrm{Br}_{0.5}\right)_{3}$, and iv $\mathrm{CsPbBr}_{3} . \mathrm{A}_{1}$ and $\mathrm{C}_{1}$ peaks are indicated in each case $\left(\mathrm{A}_{2}\right.$ and $\mathrm{C}_{2}$ are also indicated for $\mathrm{CsPb}_{0.4} \mathrm{Sn}_{0.6} \mathrm{I}_{3}$ ). (c) Energy diagram obtained with the $\mathrm{A}_{1}$ and $\mathrm{C}_{1}$ values from (b). The electrochemical band gap ( $E_{\mathrm{g}}{ }^{\mathrm{qp}}$ ) is shown in black color, and the optical band gap $\left(E_{\mathrm{g}}{ }^{\mathrm{p}}\right)$ is in gray color for comparison. (d) Comparison between the values obtained in the present study trough CV and UPS and previous reports.

band gap $\left(E_{\mathrm{g}}{ }^{\mathrm{op}}\right)$, determined through optical absorption and PL measurements. Figure $2 \mathrm{a}$ shows a representative cyclic voltammogram of a $\mathrm{Pt}$ working electrode in a $\mathrm{CsPbI}_{3} \mathrm{QDs}$ solution at $100 \mathrm{mV} \mathrm{s}^{-1}$. The irreversible peaks at $-1 \mathrm{~V}$ vs NHE and at $0.74 \mathrm{~V}$ vs NHE correspond to $\mathrm{C}_{1}$ and $\mathrm{A}_{1}$, respectively. This irreversibility has been attributed to partial $Q D$ degradation after charge transfer. ${ }^{11,12}$ The potential difference $\left(E_{\mathrm{g}} \mathrm{qp}\right)$ between $\mathrm{C}_{1}$ and $\mathrm{A}_{1}(1.74 \mathrm{~V})$ is in excellent agreement with the $E_{\mathrm{g}}^{\text {op }}$ value, obtained by absorbance and PL measurements (Supporting Information Table S2). Identical measurements were performed on $\mathrm{CsPb}_{0.4} \mathrm{Sn}_{0.6} \mathrm{I}_{3}, \mathrm{CsPb}$ $\left(\mathrm{I}_{0.5} \mathrm{Br}_{0.5}\right)_{3}$, and $\mathrm{CsPbBr}_{3}$ QDs, and Figure $2 \mathrm{~b}$ shows the voltammograms corresponding to all tested samples, recorded at $100 \mathrm{mV} \mathrm{s}^{-1}$. The corresponding $A_{1}$ and $C_{1}$ peaks are indicated in all cases, and from these values, $E_{\mathrm{g}} \mathrm{qp}$ was calculated. Supporting Information Figure S4 displays the cyclic voltammograms recorded for the same dispersion of $\mathrm{CsPb}_{0.4} \mathrm{Sn}_{0.6} \mathrm{I}_{3}$ QDs at different scan rates $(\nu)$. The linear dependence between the peak current values of $A_{1}$ and $C_{1}$ versus $\nu^{1 / 2}$ confirms the diffusion-controlled process, validating the treatment of the perovskite $\mathrm{QDs}$ as isolated quasiparticles. ${ }^{12}$ It is worth mentioning that some additional peaks have been identified as $\mathrm{C}_{2}$ and $\mathrm{A}_{2}$ in the reported voltammograms for $\mathrm{CsPb}_{0.4} \mathrm{Sn}_{0.6} \mathrm{I}_{3}$ QDs, which have been ascribed to trap-to-band transitions. ${ }^{22}$ All of the results are included in the energy diagram of Figure $2 c$ and Supporting Information Table S2, also including $E_{\mathrm{g}}^{\text {op }}$ calculated from optical measurements. In all cases, the correspondence between both electrochemical and optical band gaps is excellent. Furthermore, ultraviolet photoelectron spectroscopy (UPS) was also employed to corroborate the trend of the band positions of the perovskite QDs by the determination of the VB (Supporting Information Figure S5), and the obtained values are summarized in Figure $2 \mathrm{~d}$, also showing very good agreement with both electro- chemical and optical measurements. Indeed, the values obtained in this work are also in reasonably good agreement with those reported with electrochemical measurements of perovskites nanocrystals, ${ }^{16}$ UPS of films, ${ }^{24}$ and photoelectron yield spectroscopy (PYS) of colloidal QDs, ${ }^{22}$ as shown in Figure $2 \mathrm{~d}$. Note that although identical energy positions should not be expected from electrochemistry and UPS, due to the sensitivity of $E_{\mathrm{g}}^{\mathrm{qp}}$ to the QDs environment, a similar trend is obtained. To further validate the energetic alignment of the different QDs tested, steady-state PL measurements were carried out to monitor the change in emission properties of the QDs upon addition of a second chromophore to demonstrate straddling gap (type-I) or staggered gap (type-II) alignment between different QD combinations (further details in the Supporting Information). From these experiments, type-I alignment between $\mathrm{CsPbI}_{3}$ and $\mathrm{CsPb}_{0.4} \mathrm{Sn}_{0.6} \mathrm{I}_{3}$ was confirmed; meanwhile, type-II alignment was observed between $\mathrm{CsPb}_{0.4} \mathrm{Sn}_{0.6} \mathrm{I}_{3} / \mathrm{CsPbBr}$ and $\mathrm{CsPbBr} 3 / \mathrm{CsPbI}_{3}$ combinations (Supporting Information Figure S6).

Detailed information on the alignment of perovskite $Q D$ energy levels allows reliable evaluation of the suitability of these systems to promote the photocatalytic and photoelectrochemical degradation of different organic compounds. Accordingly, as a proof-of-concept, we selected 2-mercaptobenzothiazole (MBT). The oxidation of this compound has been reported between 0.47 and $1 \mathrm{~V}$ vs NHE (depending on the working electrode, MBT conditions, etc.). ${ }^{25}$ This organic pollutant is expected to be degraded by photoexcited holes generated in the perovskite QDs upon illumination. This compound is an important member of the benzothiazole group of heterocyclic aromatic compounds. It is widely used in rubber additive production, particularly as an accelerator of sulfur polymerization (vulcanization). It has been also employed as a biocorrosion inhibitor in industrial cooling 
(a)

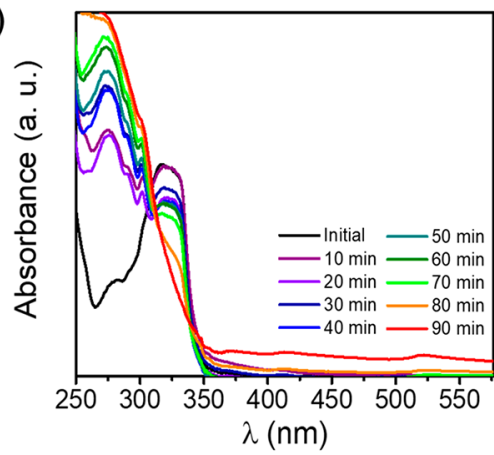

(c)

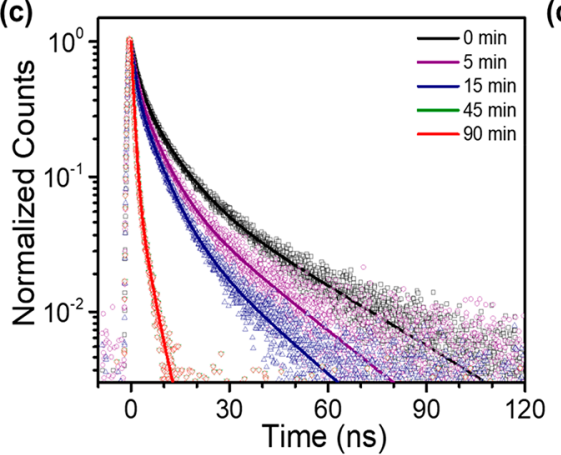

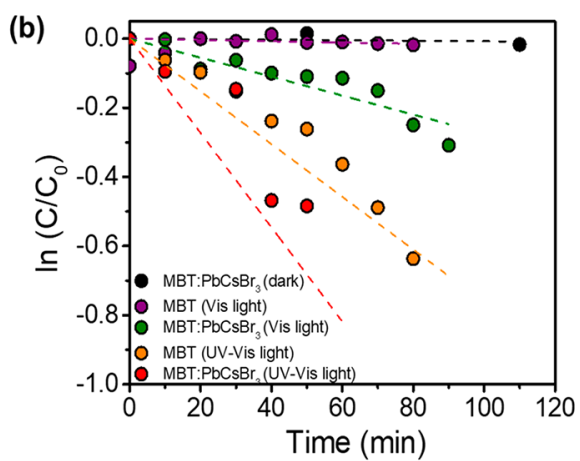

(d)

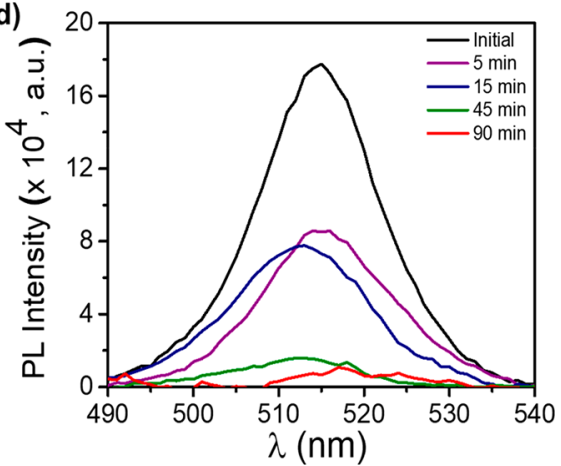

Figure 3. (a) Absorbance spectra for MBT photodegradation in the presence of $\mathrm{CsPBrr}_{3}$ QDs under $100 \mathrm{~mW} \mathrm{~cm}^{-2}$ irradiation with a UV filter (for better appreciation, the absorbance spectra of $\mathrm{CsPbBr}_{3}$ QDs were subtracted from the global spectra). (b) Relative change of the MBT concentration with time in different conditions. (c) Time-resolved PL decays (scatter symbols; lines are fitted curves through triexponential decay). (d) PL emission before addition of MBT (0 min) and after, under $100 \mathrm{~mW} \mathrm{~cm}{ }^{-2}$ irradiation with UV filter.

systems, in the galvanic industry, and also as a fungicide, herbicide, and antialgal agent. ${ }^{26,27}$ It is poorly biodegradable and exhibits aquatic toxicity, induces tumors in aquatic organisms, and stands as one of the most frequent allergens and a human carcinogen. ${ }^{28}$ All of the tested QDs have suitable band positions for hole transfer to $\mathrm{MBT}$, as shown in Supporting Information Figure S9a. However, we specifically focused on $\mathrm{CsPBr}_{3}$ QDs because the optical absorbance of these QDs does not overlap with the characteristic band of MBT at $320 \mathrm{~nm}$, which is monitored during photocatalytic degradation (see Supporting Information Figure S9b).

Consequently, we have tracked the photocatalytic degradation of MBT in the presence of $\mathrm{CsPBBr}_{3}$ QDs by following the evolution of this characteristic absorbance band, as shown in Figure 3a. In order to unambiguously determine the role of the perovskite QDs during the photodegradation of MBT, control experiments were carried out without the QDs in the solution and with and without a UV filter during light irradiation (Supporting Information Figure $\mathrm{S} 10 \mathrm{a}-\mathrm{c}$ ). The results are summarized in Figure $3 \mathrm{~b}$ as the relative concentration of the pollutant as $\ln \left(C / C_{0}\right)$ versus time. Without the presence of $\mathrm{CsPbBr}_{3}$ QDs, only UV light is effective toward the degradation of MBT, while no degradation takes place in the dark or under visible illumination, in good correspondence with previous reports. ${ }^{29}$ Upon addition of the $\mathrm{CsPbBr}_{3}$ QDs, significantly faster degradation rates are observed under both UV and visible illumination. The linear trend of the photodegradation kinetics can be approximated by a pseudofirst-order rate law, from which the rate constant $(k)$ can be calculated as $\ln \left(\frac{C}{C_{0}}\right)=k t$, where $t$ is the irradiation time. The obtained values are shown in Table 1. Additional control experiments with QDs and MBT in the dark were carried out
Table 1. Rate Constants of MBT Photodegradation with or without $\mathrm{CsPbr}_{3}$ QDs under Different Illumination Conditions, Obtained through Optical Absorbance Measurements in Figure $3 b$

\begin{tabular}{ll}
\multicolumn{1}{c}{ condition } & $|k| \mathrm{h}^{-1}$ \\
$\mathrm{MBT}$ (UV-vis light) & 0.5346 \\
$\mathrm{MBT}: \mathrm{CsbBr}$ (UV-vis light) & 1.0188 \\
$\mathrm{MBT}$ (vis light) & 0.0303 \\
$\mathrm{MBT}: \mathrm{CsbBr}_{3}$ (vis light) & 0.1812 \\
$\mathrm{MBT}: \mathrm{CsbBr}_{3}$ (dark) & 0.0099 \\
\hline
\end{tabular}

(Supporting Information Figure S10d) to rule out any possible competing chemical degradation mechanism. Remarkably, upon addition of the perovskite QDs in the MBT solution, the degradation rate is doubled for experiments with UV-vis irradiation and multiplied by a factor of six for experiments with visible illumination.

Effective charge transfer from the $\mathrm{CsPBr}_{3}$ QDs to MBT was confirmed through time-resolved photoluminescence (TRPL) and steady-state PL emission carried out at different times; see Figure 3c,d, respectively. The solution was saturated with MBT for these experiments in order to avoid mass transfer limitations. Surprisingly, the emission quenching took place over $45 \mathrm{~min}$, and the PL average lifetime $\left(\tau_{\text {avg }}\right)$ changed from 26.3 to $11 \mathrm{~ns}$ over $45 \mathrm{~min}$. Note that after $45 \mathrm{~min}$ there was no emission or $\tau_{\text {avg }}$ difference (Supporting Information Table S4). This slow quenching process suggests that the interaction between $\mathrm{Cs} \mathrm{PbBr}_{3}$ QDs and $\mathrm{MBT}$ needs some time to proceed. In contrast, the charge transfer process between QDs and acceptor molecules generally takes place in less than $1 \mu \mathrm{s} .{ }^{30}$ Because the perovskite QDs were covered by long-carbonchain (C-18) ligands, i.e., oleic amine and oleic acid, which are in dynamic equilibrium between adsorption and desorption in 

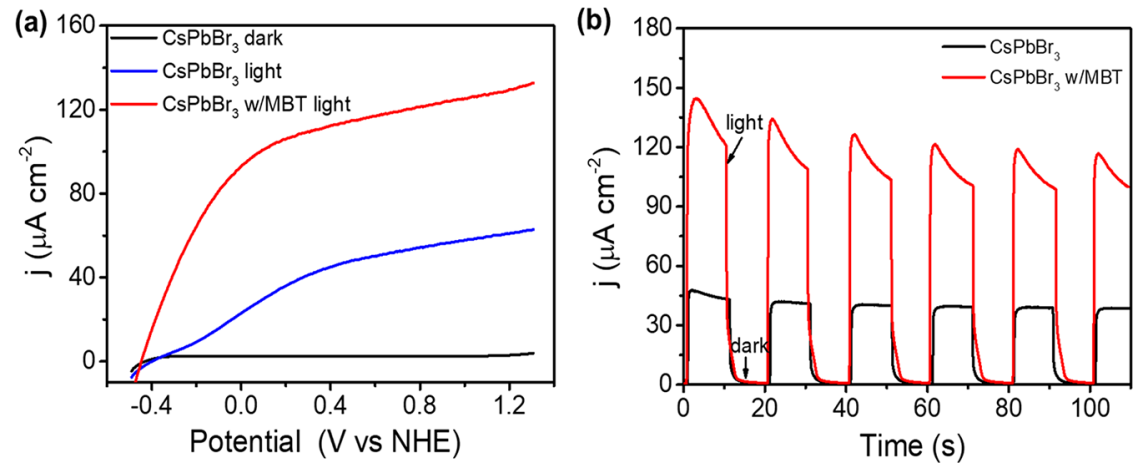

Figure 4. (a) LSV of the $\mathrm{CsPbBr}_{3} / \mathrm{c}-\mathrm{TiO}_{2} / \mathrm{FTO}$ film in $100 \mathrm{mM} \mathrm{Bu}_{4} \mathrm{NPF}_{6}$ in DCM solution, with and without MBT added to the electrolyte. (b) Chronoamperometry measurement in the $\mathrm{CsPbBr} / \mathrm{c}-\mathrm{TiO}_{2} / \mathrm{FTO}$ film under chopped $100 \mathrm{~mW} \mathrm{~cm}{ }^{-2}$ illumination with and without MBT added to the electrolyte solution, at a constant potential of $1 \mathrm{~V}$ vs NHE.

the solution, ${ }^{31}$ we speculate that even in saturated MBT solution $\mathrm{MBT}$ can progressively replace these ligands with time (tens of minutes), binding to the surface of $\mathrm{CsPbr}_{3}$ QDs. Therefore, the photocatalytic degradation of MBT occurred more significantly after 20 min under UV-vis illumination. It is also worth noting the slight blue shift observed in the PL spectra of Figure $3 \mathrm{~d}$ with time, which can be related to $\mathrm{Cs} \mathrm{PbBr}_{3}$ instabilities under ambient conditions, as previously described in pure $\mathrm{CsPbBr}_{3}$ nanocrystal-based films. ${ }^{32}$

Additional confirmation of the degradation of MBT was provided by electrospray mass spectroscopy (ESI-MS) analysis (Supporting Information Figure S11). The experiments were performed with a control sample (containing only MBT dissolved in hexane) and with an MBT solution with $\mathrm{Cs} \mathrm{PbBr}_{3}$ QDs before and after illumination at $100 \mathrm{~mW} \mathrm{~cm} \mathrm{~cm}^{-2}$ for 100 min with a UV filter. The initial $m / z(167.9937)$ characteristic peak of MBT clearly disappears after 100 min of irradiation, confirming the total degradation of the organic compound.

In order to further understand the carrier dynamics of the $\mathrm{CsPBr}_{3}$ QDs/MBT system, we deposited a $300 \mathrm{~nm}$ thick layer of perovskite QDs on a transparent conductive substrate with a thin electron selective layer $\left(\mathrm{FTO} / \mathrm{TiO}_{2}\right)$, confining the QDs onto the electrode surface. The photoelectrochemical behavior of the tested photoelectrodes was characterized in a three-electrode configuration using a $100 \mathrm{mM} \mathrm{Bu}_{4} \mathrm{NPF}_{6}$ in DCM with and without MBT. Linear sweep voltammograms (LSVs) in the optimized potential range for the $\mathrm{CsPbr}_{3} /$ $\mathrm{TiO}_{2} /$ FTO electrode (see Supporting Information Figure $\mathrm{S} 12 \mathrm{a})$ with and without the addition of MBT are shown in Figure 4. In the dark, no current is extracted (Figure 4a), while under $100 \mathrm{~mW} \mathrm{~cm} \mathrm{~cm}^{-2}$ illumination, an anodic photocurrent is measured, characteristic of an n-type semiconductor photoanode injecting minority carriers (holes) into the solution. When MBT is present in the solution, this anodic photocurrent significantly increases to a maximum of $140 \mu \mathrm{A} \mathrm{cm} \mathrm{cm}^{-2}$, confirming hole transfer from the $\mathrm{CsPBBr}_{3}$ to the MBT. The photoelectrochemical behavior is stable at least for the time scale that the photoelectrochemical tests are carried out, as evidenced from chopped-light chronoamperometric tests shown in Figure $4 \mathrm{~b}$. The n-type behavior of the films is also confirmed by the cathodic shift of the open-circuit potential (OCP) under illumination (see Supporting Information Figure S12b). Mott-Schottky analysis revealed a donor density of $6.77 \times 10^{19} \mathrm{~cm}^{-3}$ and a flat band potential of $-0.109 \mathrm{~V}$ vs NHE (Supporting Information Figure S13), also in good correspondence with the $\mathrm{CB}$ of the perovskite $\mathrm{QD}$ suspensions extracted by CV and UPS (Figure 1).

The stability of the $\mathrm{CsPbBr}_{3} / \mathrm{c}-\mathrm{TiO}_{2} / \mathrm{FTO}$ films during the PEC measurements was evaluated through absorbance and PL measurements (Supporting Information Figures S14 and S15) after photoelectrochemical testing. Remarkably, the QD films maintain their mechanical integrity, although the PL is less intense after PEC treatment, evidencing the interaction between MBT and the $\mathrm{CsPbBr}$ surface. In any case, we recognize that the stability of these systems must be significantly improved to target real technological applications. Some promising strategies to stabilize these QDs by conformal coating with metal oxide layers have been reported. ${ }^{33}$ The toxicity of lead is also a significant limitation for environmental applications, and although the photoelectrochemical route confines $\mathrm{Pb}$ onto the electrode surface, alleviating this toxicity problem, the total replacement of this element by other more benign constituents must be urgently addressed in the near future. ${ }^{34,35}$ Indeed, very promising results have been reported on $\mathrm{Pb}$-free perovskite systems, like $\mathrm{Cs}_{2} \mathrm{TiBr}_{6},{ }^{36,37}$ featuring good stability, although performance still lags behind that of their $\mathrm{Pb}$-containing counterparts. It is expected that the achievements developed for the nanoparticles employed in the present study can be easily extrapolated to other systems in the near future.

In summary, we have shown that the outstanding optoelectronic properties of perovskite QDs can be harnessed for both the photocatalytic (as dispersed nanoparticles) and photoelectrochemical (as thin films) degradation of organic compounds, using MBT as a proof-of-concept. The systematic evaluation of the environmental conditions needed for stable operation of these systems along with the determination of the energy levels by spectroscopic (absorbance, PL, UPS) and electrochemical (CV) methods is key to understand the potential electrochemical reactions accessible for these systems. The obtained results unambiguously confirm that hole injection from perovskite QDs to MBT takes place during the photocatalytic and photoelectrochemical (photocurrent at $1 \mathrm{~V}$ vs NHE, $j_{\mathrm{ph}}=150 \mu \mathrm{A} \mathrm{cm} \mathrm{cm}^{-2}$ ) oxidation of MBT with $\mathrm{CsPbBr}_{3}$ QDs, confirming the effective degradation of the molecule by ESI-MS. These results constitute a significant step forward in the application of perovskite QDs for solar-driven catalytic processes, opening promising perspectives in the fields of solar synthesis, photocatalysis, and photoelectrochemistry. This study could have important implications not only for the family of perovskite QDs reported here but also for the 
increased number of new perovskite and perovskite-related compounds that have appeared recently.

\section{ASSOCIATED CONTENT}

\section{S Supporting Information}

The Supporting Information is available free of charge on the ACS Publications website at DOI: 10.1021/acs.jpclett.8b03849.

Experimental details, further optical and microscopic characterization of the as-prepared perovskite QDs, electrochemical tests to demonstrate the diffusion controlled electrochemical process of perovskite QDs, ultraviolet photon spectroscopy (UPS) measurements, $\mathrm{PL}$ measurements to validate discussion of the dilution effect, photocatalytic measurements for the degradation of MBT, ESI-MS measurements, electrochemical measurements in perovskite QDs films, Mott-Schottky plot of a perovskite $\mathrm{QD}$ film, and characterization of the stability of QD films under photoelectrochemical oxidation of MBT (PDF)

\section{AUTHOR INFORMATION}

\section{Corresponding Authors}

*E-mail: sero@uji.es (I.M.-S.).

*E-mail: sjulia@uji.es (S.G.).

\section{ORCID}

Miguel García-Tecedor: 0000-0002-9664-4665

Iván Mora-Seró: 0000-0003-2508-0994

Sixto Gimenez: 0000-0002-4522-3174

\section{Notes}

The authors declare no competing financial interest.

\section{ACKNOWLEDGMENTS}

We would like to acknowledge financial support from the European Commission via ERC Consolidator Grant (724424 No-LIMIT), Ministerio de Ciencia, Innovación y Universidades of Spain (ENE2017-85087-C3-1-R), University Jaume I (SOLENPE UJI-B2016-05), and the Generalitat Valenciana through the Santiago Grisolia Program, Grant 2015-031. Serveis Centrals at UJI (SCIC) are also acknowledged for assistance with TEM and XRD characterization along with the Molecular Foundry of Lawrence Berkeley National Laboratory for UPS measurements and CONACyT-SENER-2015-07 Project 269386.

\section{REFERENCES}

(1) Protesescu, L.; Yakunin, S.; Bodnarchuk, M. I.; Krieg, F.; Caputo, R.; Hendon, C. H.; Yang, R. X.; Walsh, A.; Kovalenko, M. V. Nanocrystals of Cesium Lead Halide Perovskites $\left(\mathrm{CsPbX}_{3}, \mathrm{X}=\mathrm{Cl}, \mathrm{Br}\right.$, and I): Novel Optoelectronic Materials Showing Bright Emission with Wide Color Gamut. Nano Lett. 2015, 15, 3692-3696.

(2) Song, J.; Li, J.; Li, X.; Xu, L.; Dong, Y.; Zeng, H. Quantum Dot Light-Emitting Diodes Based on Inorganic Perovskite Cesium Lead Halides $\left(\mathrm{CsPbX}_{3}\right)$. Adv. Mater. 2015, 27, 7162-7167.

(3) Swarnkar, A.; Chulliyil, R.; Ravi, V. K.; Irfanullah, M.; Chowdhury, A.; Nag, A. Colloidal Cs $\mathrm{PbBr}_{3}$ Perovskite Nanocrystals: Luminescence beyond Traditional Quantum Dots. Angew. Chem., Int. Ed. 2015, 54, 15424-15428.

(4) Yakunin, S.; Protesescu, L.; Krieg, F.; Bodnarchuk, M. I.; Nedelcu, G.; Humer, M.; De Luca, G.; Fiebig, M.; Heiss, W.; Kovalenko, M. V. Low-threshold Amplified Spontaneous Emission and Lasing from Colloidal Nanocrystals of Caesium Lead Halide Perovskites. Nat. Commun. 2015, 6, 8056.
(5) Buin, A.; Comin, R.; Xu, J.; Ip, A. H.; Sargent, E. H. HalideDependent Electronic Structure of Organolead Perovskite Materials. Chem. Mater. 2015, 27, 4405-4412.

(6) Gao, G.; Xi, Q.; Zhou, H.; Zhao, Y.; Wu, C.; Wang, L.; Guo, P.; $\mathrm{Xu}, \mathrm{J}$. Novel Inorganic Perovskite Quantum Dots for Photocatalysis. Nanoscale 2017, 9, 12032-12038.

(7) Huang, H.; Yuan, H.; Zhao, J.; Solís-Fernández, G.; Zhou, C.; Seo, J. W.; Hendrix, J.; Debroye, E.; Steele, J. A.; Hofkens, J.; Long, J.; Roeffaers, M. B. J. C(sp3)-H Bond Activation by Perovskite Solar Photocatalyst Cell. ACS Energy Lett. 2019, 4, 203-208.

(8) Hou, J.; Cao, S.; Wu, Y.; Gao, Z.; Liang, F.; Sun, Y.; Lin, Z.; Sun, L. Inorganic Colloidal Perovskite Quantum Dots for Robust Solar $\mathrm{CO}_{2}$ Reduction. Chem. - Eur. J. 2017, 23, 9481-9485.

(9) Xu, Y.-F.; Yang, M.-Z.; Chen, B.-X.; Wang, X.-D.; Chen, H.-Y.; Kuang, D.-B.; Su, C.-Y. A CsPbBr 3 Perovskite Quantum Dot/ Graphene Oxide Composite for Photocatalytic $\mathrm{CO}_{2}$ Reduction. J. Am. Chem. Soc. 2017, 139, 5660-5663.

(10) Zhou, L.; Xu, Y.-F.; Chen, B.-X.; Kuang, D.-B.; Su, C.-Y. Synthesis and Photocatalytic Application of Stable Lead-Free $\mathrm{Cs}_{2} \mathrm{AgBiBr}_{6}$ Perovskite Nanocrystals. Small 2018, 14, 1703762.

(11) Haram, S. K.; Quinn, B. M.; Bard, A. J. Electrochemistry of CdS Nanoparticles: A Correlation between Optical and Electrochemical Band Gaps. J. Am. Chem. Soc. 2001, 123, 8860-8861.

(12) Inamdar, S. N.; Ingole, P. P.; Haram, S. K. Determination of Band Structure Parameters and the Quasi-Particle Gap of CdSe Quantum Dots by Cyclic Voltammetry. ChemPhysChem 2008, 9, 2574-2579.

(13) Kucur, E.; Riegler, J.; Urban, G. A.; Nann, T. Determination of Quantum Confinement in CdSe Nanocrystals by Cyclic Voltammetry. J. Chem. Phys. 2003, 119, 2333-2337.

(14) Markad, G. B.; Battu, S.; Kapoor, S.; Haram, S. K. Interaction between Quantum Dots of CdTe and Reduced Graphene Oxide: Investigation through Cyclic Voltammetry and Spectroscopy. J. Phys. Chem. C 2013, 117, 20944-20950.

(15) Haram, S. K.; Kshirsagar, A.; Gujarathi, Y. D.; Ingole, P. P.; Nene, O. A.; Markad, G. B.; Nanavati, S. P. Quantum Confinement in CdTe Quantum Dots: Investigation through Cyclic Voltammetry Supported by Density Functional Theory (DFT). J. Phys. Chem. C 2011, 115, 6243-6249.

(16) Ravi, V. K.; Markad, G. B.; Nag, A. Band Edge Energies and Excitonic Transition Probabilities of Colloidal CsPbX $(\mathrm{X}=\mathrm{Cl}, \mathrm{Br}, \mathrm{I})$ Perovskite Nanocrystals. ACS Energy Lett. 2016, 1, 665-671.

(17) Samu, G. F.; Scheidt, R. A.; Kamat, P. V.; Janáky, C. Electrochemistry and Spectroelectrochemistry of Lead Halide Perovskite Films: Materials Science Aspects and Boundary Conditions. Chem. Mater. 2018, 30, 561-569.

(18) Grånäs, O.; Vinichenko, D.; Kaxiras, E. Establishing the Limits of Efficiency of Perovskite Solar Cells from First Principles Modeling. Sci. Rep. 2016, 6, 36108.

(19) Vitoreti, A. B. F.; Agouram, S.; Solis de la Fuente, M.; MuñozSanjosé, V.; Schiavon, M. A.; Mora-Seró, I. Study of the Partial Substitution of $\mathrm{Pb}$ by $\mathrm{Sn}$ in $\mathrm{Cs}-\mathrm{Pb}-\mathrm{Sn}-\mathrm{Br}$ Nanocrystals Owing to Obtaining Stable Nanoparticles with Excellent Optical Properties. J. Phys. Chem. C 2018, 122, 14222-14231.

(20) Eperon, G. E.; Paterno, G. M.; Sutton, R. J.; Zampetti, A.; Haghighirad, A. A.; Cacialli, F.; Snaith, H. J. Inorganic Caesium Lead Iodide Perovskite Solar Cells. J. Mater. Chem. A 2015, 3, 1968819695.

(21) Chen, M.; Zou, Y.; Wu, L.; Pan, Q.; Yang, D.; et al. Solvothermal Synthesis of High-Quality All-Inorganic Cesium Lead Halide Perovskite Nanocrystals: From Nanocube to Ultrathin Nanowire. Adv. Funct. Mater. 2017, 27, 1701121.

(22) Liu, F.; Ding, C.; Zhang, Y.; Ripolles, T. S.; Kamisaka, T.; Toyoda, T.; Hayase, S.; Minemoto, T.; Yoshino, K.; Dai, S. Q.; et al. Colloidal Synthesis of Air-Stable Alloyed $\mathrm{CsSn}_{1-\mathrm{x}} \mathrm{Pb}_{\mathrm{x}} \mathrm{I}_{3}$ Perovskite Nanocrystals for Use in Solar Cells. J. Am. Chem. Soc. 2017, 139, $16708-16719$.

(23) Serdechnova, M.; Ivanov, V. L.; Domingues, M. R. M.; Evtuguin, D. V.; Ferreira, M. G. S.; Zheludkevich, M. L. Photo- 
degradation of 2-Mercaptobenzothiazole and 1,2,3-Benzotriazole Corrosion Inhibitors in Aqueous Solutions and Organic Solvents. Phys. Chem. Chem. Phys. 2014, 16, 25152-25160.

(24) Akkerman, Q. A.; Gandini, M.; Di Stasio, F.; Rastogi, P.; Palazon, F.; Bertoni, G.; Ball, J. M.; Prato, M.; Petrozza, A.; Manna, L. Strongly Emissive Perovskite Nanocrystal Inks for High-Voltage Solar Cells. Nat. Energy 2017, 2, 16194.

(25) Shahrokhian, S.; Amini, M. K.; Mohammadpoor-Baltork, I.; Tangestaninejad, S. Potentiometric Detection of 2-Mercaptobenzimidazole and 2-Mercaptobenzothiazole at Cobalt Phthalocyanine Modified Carbon-Paste Electrode. Electroanalysis 2000, 12, 863-867.

(26) Clarke, B. O.; Smith, S. R. Review of 'Emerging' Organic Contaminants in Biosolids and Assessment of International Research Priorities for the Agricultural Use of Biosolids. Environ. Int. 2011, 37, 226-47.

(27) De Wever, H.; Verachtert, H. Biodegradation and Toxicity of Benzothiazoles. Water Res. 1997, 31, 2673-2684.

(28) Sorahan, T. Cancer Risks in Chemical Production Workers Exposed to 2-Mercaptobenzothiazole. Occup. Environ. Med. 2008, 66, 269-273.

(29) Li, F. B.; Li, X. Z.; Hou, M. F.; Cheah, K. W.; Choy, W. C. H. Enhanced Photocatalytic Activity of $\mathrm{Ce}^{3+}-\mathrm{TiO}_{2}$ for 2-Mercaptobenzothiazole Degradation in Aqueous Suspension for Odour Control. Appl. Catal., A 2005, 285, 181-189.

(30) Hines, D. A.; Kamat, P. V. Quantum Dot Surface Chemistry: Ligand Effects and Electron Transfer Reactions. J. Phys. Chem. C 2013, 117, 14418-14426.

(31) Grisorio, R.; Debellis, D.; Suranna, G. P.; Gigli, G.; Giansante, C. The Dynamic Organic/Inorganic Interface of Colloidal $\mathrm{PbS}$ Quantum Dots. Angew. Chem., Int. Ed. 2016, 55, 6628-6633.

(32) Draguta, S.; Sharia, O.; Yoon, S. J.; Brennan, M. C.; Morozov, Y. V.; Manser, J. M.; Kamat, P. V.; Schneider, W. F.; Kuno, M. Rationalizing the Light-Induced Phase Separation of Mixed Halide Organic-Inorganic Perovskites. Nat. Commun. 2017, DOI: 10.1038/ s41467-017-00284-2.

(33) Loiudice, A.; Saris, S.; Oveisi, E.; Alexander, D. T. L.; Buonsanti, R. CsPbBr 3 QD/AlO $/ \mathrm{Al}_{\mathrm{x}}$ Inorganic Nanocomposites with Exceptional Stability in Water, Light, and Heat. Angew. Chem., Int. Ed. 2017, 56, 10696-10701.

(34) Zhang, Q.; Hao, F.; Li, J.; Zhou, Y.; Wei, Y.; Lin, H. Perovskite Solar Cells: Must Lead Be Replaced - and Can it Be Done? Sci. Technol. Adv. Mater. 2018, 19, 425-442.

(35) Pazoki, M.; Jacobsson, T. J.; Hagfeldt, A.; Boschloo, G.; Edvinsson, T. Effect of Metal Cation Replacement on the Electronic Structure of Metalorganic Halide Perovskites: Replacement of Lead with Alkaline-Earth Metals. Phys. Rev. B: Condens. Matter Mater. Phys. 2016, 93, 144105.

(36) Volonakis, G.; Filip, M. R.; Haghighirad, A. A.; Sakai, N.; Wenger, B.; Snaith, H. J.; Giustino, F. Lead-Free Halide Double Perovskites via Heterovalent Substitution of Noble Metals. J. Phys. Chem. Lett. 2016, 7, 1254-1259.

(37) Ju, M.-G.; Chen, M.; Zhou, Y.; Garces, H. F.; Dai, J.; Ma, L.; Padture, N. P.; Zeng, X. C. Earth-Abundant Nontoxic Titanium(IV)based Vacancy-Ordered Double Perovskite Halides with Tunable 1.0 to $1.8 \mathrm{eV}$ Bandgaps for Photovoltaic Applications. ACS Energy Lett. 2018, 3, 297-304. 